\title{
An assessment of the financial efficiency of a heat recovery system from graywater in a hotel
}

\author{
Aleksandra Mazur ${ }^{1, *}$ \\ ${ }^{1}$ Rzeszów University of Technology, Faculty of Civil and Environmental Engineering and \\ Architecture, Department of Infrastructure and Sustainable Development, al. Powstańców Warszawy \\ 12, 35-959 Rzeszów, Poland
}

\begin{abstract}
The purpose of the article is to determine the profitability of investing in a graywater heat recovery system in a hotel facility located in south-eastern Poland whichis dependent on three heat sources for the domestic hot water preparation system, i.e. gas boiler, biomass boiler and electric heater. There were also various options for accommodation use: $25 \%, 50 \%, 75 \%$ and $100 \%$ occupancy of the hotel. The research was focused on the most frequently used methods for the absolute assessment of the effectiveness of investment projects enabling the creation of an objective criterion. Thus, both the simple method - Simple Pay Back Period SPBP and dynamic methods based on the discount account were used in calculations: Net Present Value NPV, Internal Rate of Return IRR, Profitability Index PI, Discounted Pay Back Period DPBP. The analysis also includes the annual increase in the purchase price of energy carriers. The conducted research has shown that in most cases the installation of the DWHR (Drain Water Heat Recovery) system is beneficial and profitable to the investor.
\end{abstract}

\section{Introduction}

One of the current objectives of modern energy policy is the rational management of the natural resources of the Earth, including fossil fuels still available, with a focus on rationalization of their consumption [1]. Due to the high operational energy consumption of construction facilities, it seems important to increase the energy efficiency of heating and heating installations, including systems for supplying the building with hot water, which is one of the priorities of the European Union's energy economy [2]. Hence the activities in the field of replacing low-efficient heating boilers with modern energy-saving devices, and the modernization of the installation allowing for the maximization of work efficiency or the integration of various installation systems [3-5]. Another way to reduce the energy consumption in a building can also be an investment in renewable energy sources $[6,7]$, including the installation of DWHR (Drain Water Heat Recovery) enabling the recovery of waste heat from sewage systems [8-10].

The system of heat recovery from graywater is therefore especially more profitable the higher the consumption of hot water in the building [11]. It seems that in service facilities such as laundries, hotels, swimming pools, which are examples of buildings with a high

\footnotetext{
*Corresponding author: a.mazur@prz.edu.pl
} 
energy demand for hot water purposes, an investment involving the assembly of the DWHR system may prove particularly beneficial.

An investment in renewable energy sources, including the Drain Water Heat Recovery system cannot only be beneficial because of its positive environmental effect, but above all, it should be profitable for the potential investor as only then can there be a prospect for the wider application of such systems in many construction objects.

The purpose of the article is to determine the economic efficiency of the heat recovery system from graywater in a three-star hotel, implemented by equipping the sewage system to discharge used water from shower cabins into horizontal heat exchangers depending on the heat source of the building's supply of hot water and a different percentage of accommodation.

\section{Case study}

As a research object, a 3-star hotel with a usable area of $1,448 \mathrm{~m}^{2}$ and a volume of $10,000 \mathrm{~m}^{3}$ located in Rzeszów in south-eastern Poland was adopted. It is a ground floor building with a partially developed floor facing the front, without a basement. The hotel has 44 rooms, and altogether has 100 beds. A summary of the detailed rooms is shown in Table 1.

Table 1. List of hotel rooms.

\begin{tabular}{|c|c|}
\hline Type of room & Number of rooms \\
\hline Single room & 4 \\
\hline Double room & 28 \\
\hline Triple room & 8 \\
\hline Quadruple room & 4 \\
\hline
\end{tabular}

Each room has a bathroom with a shower. Due to the fact that the bathrooms in the two adjacent rooms are adjacent to each other, one horizontal DWHR heat exchanger is installed at the outflow of graywater into the two showers. The investment concerns, therefore, the installation of a total of 22 horizontal heat exchangers. The horizontal heat exchanger model A1000 EcoDrain TM [12] was adopted for the analysis. The principle of operation of such devices is based on the countercurrent flow of cold water and graywater. The hot water consumed during a shower bath after entering the sewage system is gravitationally directed to the horizontal heat exchanger. At the same time, the cold water fed to the exchanger under pressure is heated up by the DWHR. The heat deposited in graywater is taken over by cold water. The preheated water is then directed to the shower mixer at the place connecting the cold water instead and the cooled sewage flows to the sanitary sewage system.

In order to determine the profitability of the investment, three different variants of heat sources supplying the building's supply of hot water were adopted:

- Variant A: gas condensing boiler,

- Variant B: biomass boiler,

- Variant C: electric heater.

Due to the varying degree of occupancy of tourist facilities at different periods of time, four options for using accommodation in the analyzed hotel facility were assumed:

$-25 \%$ of used beds,

- $50 \%$ of used beds,

$-75 \%$ of used beds,

- $100 \%$ of used beds.

It was assumed that in each option the rooms are equally occupied. 


\section{Methodology}

The following indicators of the economic effectiveness of investment projects were used in the article: Net Present Value $N P V$, Internal Rate of Return IRR, Profitability Index PI, Simple Pay Back Period SPBP, Discounted Pay Back Period DPBP, wherein only one out of the above-mentioned indicators belonged to the group of simple methods for the profability assessment of an investment, and it is the Simple Pay Back Period. The other analyzed ratios are classified as dynamic methods which, by using the discount account, are a more effective and more precise tool for assessing the profitability of the undertaking [13].

Net Present Value (NPV) is calculated as the sum of all cash flows (NCF) resulting from the implementation of investments, discounted separately for each year throughout the period covered by the financial analysis, assuming a fixed discount rate. The NPV value can be expressed by the formula (1)[13]:

$$
N P V=\sum_{t=0}^{n}\left(\frac{N C F_{t}}{(1+k)^{t}}\right)
$$

where: $N C F_{t}-$ net cash flows in consecutive periods $\mathrm{t}=0$ to $\mathrm{n}$ investment life cycle,

$k$ - discount rate,

$t=0$ to $n$ - subsequent years of the life cycle of the investment.

The venture is determined as cost-effective when the value of the NPV indicator is greater than zero. When it equals zero, the investment can be realized, but it will not bring clear financial benefits for the investor (the venture is neutral).

The discount rate value for which the Net Present Value is zero $(\mathrm{NPV}=0)$ is referred to as the Internal Rate of Return and marked IRR. Its approximate value can be determined by the formula (2)[14]:

$$
I R R=r_{1}+\frac{P V \cdot\left(r_{2}-r_{1}\right)}{P V+|N V|}
$$

where: $P V$ - net present value of investments, designated for $r_{l}$,

$N V$ - net present value of investments, designated for $r_{2}$,

$r_{l}-$ discount rate for which NPV $>0$,

$r_{2}-$ discount rate for which NPV $<0$.

The venture is profitable when the IRR is higher than the assumed discount rate.

The next analyzed parameter is Profitability Index (PI), which is expressed by the formula (3) [13]:

$$
P I=\frac{\sum_{t=1}^{n} \frac{N C F_{t}{ }^{+"}}{(1+k)^{t}}}{|P V I|}
$$

where: $N C F_{t}{ }^{\prime+}{ }^{\prime}-$ positive net cash flows in subsequent periods $\mathrm{t}=1$ to $\mathrm{n}$ investment life cycle,

$P V I$ - current value of capital expenditures.

An investment task may be intended for implementation when the profitability ratio is greater than or equal to 1 . In the latter case, the undertaking is clearly profitable.

As one of the decision-making criteria, the Simple Pay Back Period (SPBP) was also used to assess the cost-effectiveness of the investment. This method estimates the length of the period $(\mathrm{OZ})$, which is necessary so that the investment outlays incurred are offset by the net 
benefits $\left(\mathrm{KN}_{\mathrm{t}}\right)$, generated in subsequent years by the venture [13]. In order to calculate the indicator, the following algorithm was adopted (4):

$$
\sum_{t=0}^{m} I=\sum_{t=m+1}^{O Z} K N_{t}
$$

where: $t=0$ to $m$ - subsequent years of the calculation period in which investment expenses are incurred,

$t=m+1-$ subsequent years of the calculation period in which net benefits are obtained.

The final analyzed financial effectiveness indicator is the Discounted Pay Back Period (DPBP), which determines the length of the period (OZ), required to balance investment outlays by discounted positive net benefits $\left(\mathrm{NCF}_{t}{ }^{\prime+}\right)$ generated by the undertaking. The equation for determining the DPBP value is as follows (5)[13]:

$$
P V I=\sum_{t=m+1}^{O Z} \frac{N C F_{t}{ }^{"+"}}{(1+k)^{t}}
$$

The shorter the payback period, the more profitable the investment is.

The data constituting the basis for estimating the indicators of economic effectiveness assessment of the investment project being analyzed is summarized in Table 2.

Table 2. Data used for financial analysis.

\begin{tabular}{|c|c|}
\hline Parameter & Parameter value \\
\hline The cost of purchasing gas in the year 0 & $0,595 € / \mathrm{m}^{3}$ \\
\hline The cost of purchasing of wood pellet in the year 0 & $200,357 € / \mathrm{t}$ \\
\hline The cost of purchasing electricity in the year 0 & $0,136 € / \mathrm{kWh}$ \\
\hline Analysis period & 30 years \\
\hline The discount rate & $5 \%$ \\
\hline The cost of purchasing DWHR, installation costs included & $630 €$ \\
\hline The annual increase in gas prices & $2 \%$ \\
\hline The annual increase in wood pellet prices & $2,5 \%$ \\
\hline The annual increase in electricity prices & $1,5 \%$ \\
\hline
\end{tabular}

In order to be able to analyze the financial effectiveness of the investment in the installation of DWHR exchangers in a hotel, it is necessary to determine the operating costs of the facility resulting from the use of a hot water preparation system for each heat source, both before the project implementation and after the installation of heat recovery from graywater. The calculation of the difference between these two values allows determining the savings resulting from the use of the DWHR system. Seasonal demand for hot water $\mathrm{Q}_{\mathrm{W}, \mathrm{nd}}$ for accepted variants on the basis of which final energy $Q_{k, W}$ is determined, i.e. the amount of energy to be delivered to the facility to prepare hot water in a given quantity and for specific parameters calculated according to the methodology presented in the Regulation [15] using the ArCaDiA-TERMO computer program 6.6. based on the data compiled in Table 3.

Calculations regarding the utilization of waste heat from sewage systems in the scope of estimating the temperature increase of preheated water flowing from the EcoDrain ${ }^{\mathrm{TM}}$ heat exchanger, as well as determining the daily and annual energy saved as a result of the gray heat recovery system in the hotel building was carried out using the calculation methodology presented in publication [16]. 
Table 3. Data used for calculations.

\begin{tabular}{|c|c|}
\hline Parameter & Parameter value \\
\hline Daily hot water consumption for 1 bed & $55 \mathrm{dm}^{3} /$ person/day \\
\hline Shower lenght & $8 \mathrm{~min} /$ person/day \\
\hline Hot water temperature & $55^{\circ} \mathrm{C}$ \\
\hline Cold water temperature & $9{ }^{\circ} \mathrm{C}$ \\
\hline The temperature of the mixed water flowing out of the showerhead & $39{ }^{\circ} \mathrm{C}$ \\
\hline Mixed water flow from the showerhead & $9,5 \mathrm{~L} / \mathrm{min}$ \\
\hline $\begin{array}{c}\text { Coefficient of hot water loss in the cabin and pipes leading to the } \\
\text { DWHR device, } x\end{array}$ & 0,96 \\
\hline Performance of DWHR heat exchanger & $37,5 \%$ \\
\hline
\end{tabular}

The basis for initiating the economic analysis of the project was to determine the investment outlays and receipts from the implementation of the investment as savings resulting from the use of the DWHR system. The cost of purchasing and assembling 22 EcoDrain ${ }^{\text {TM }}$ heat exchangers has been estimated at $€ 13860$.

\section{Calculation results and analysis}

The investment profitability analysis was carried out according to the Net Present Value NPV criterion, which is based on discounted cash flows, hence Figure 1 shows the distribution of cumulated discounted cash flows ( $\Sigma \mathrm{PV}-\mathrm{NCF}$ ) for heat source gas option $\mathrm{A}$ - condensing gas boiler, Figure 2 for variant $\mathrm{B}$ - biomass boiler, and in Figure 3 for variant $\mathrm{C}$ - electric heater. It is assumed that the investment is profitable then, when the profits generated by the project, after taking into account the discount account, will offset the capital expenditures.

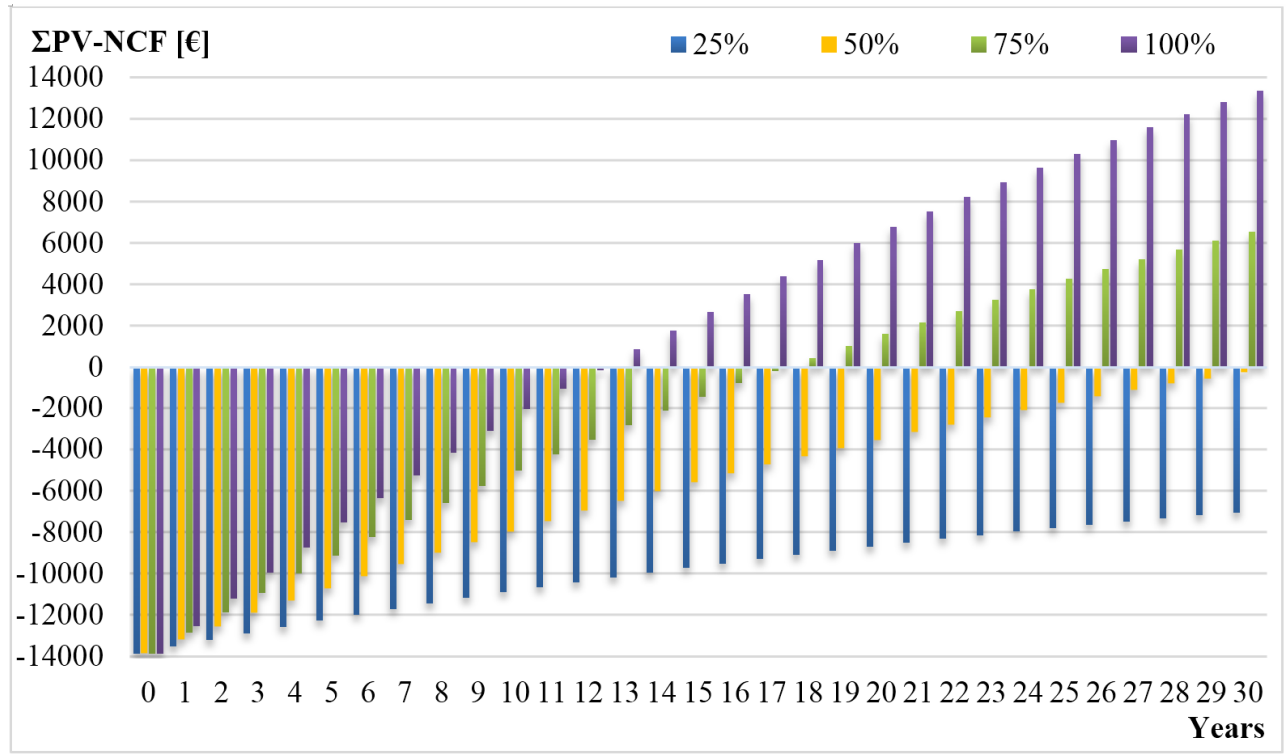

Fig. 1. Cumulative discounted cash flows for variant A of the heat source in the building. 


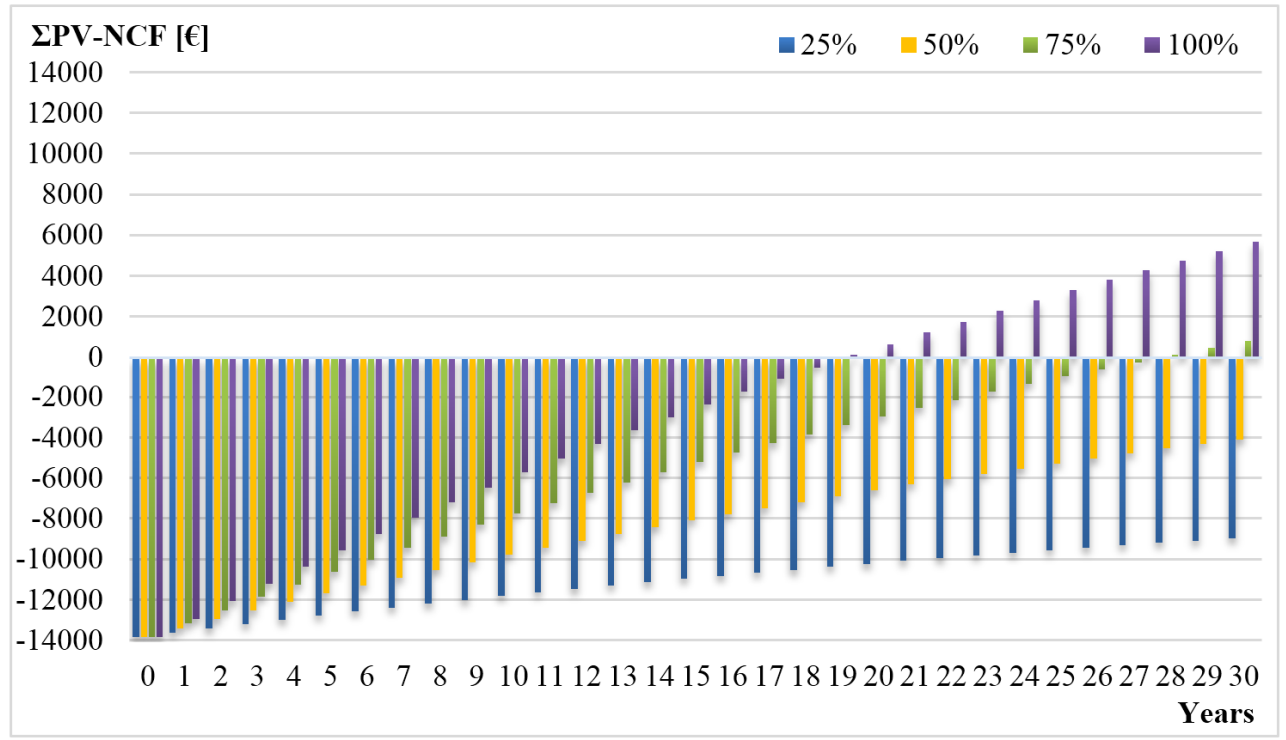

Fig. 2. Cumulative discounted cash flows for variant $B$ of the heat source in the building.

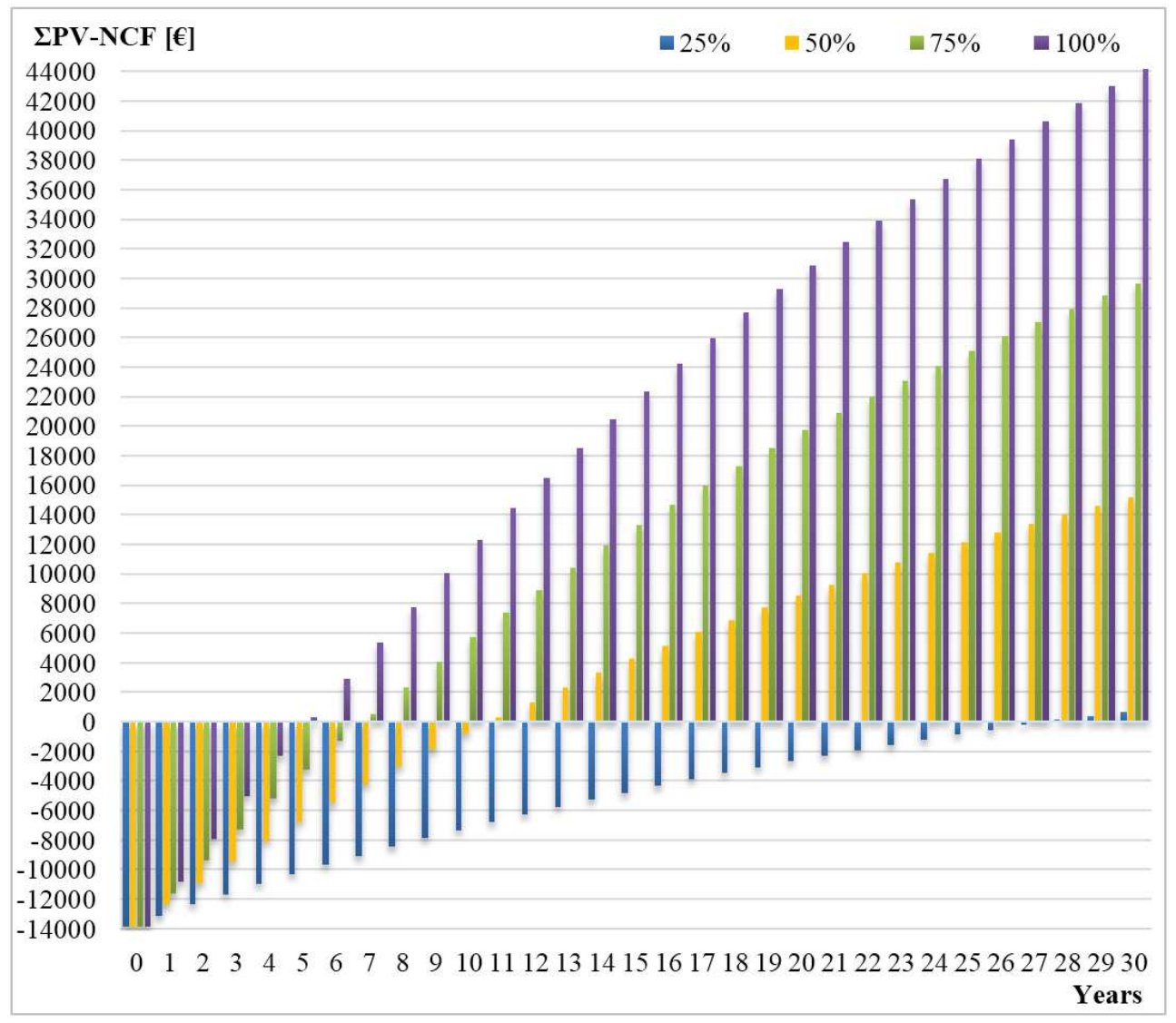

Fig. 3. Cumulative discounted cash flows for variant $\mathrm{C}$ of the heat source in the building. 
As is identified in Figure 1, Figure 2 and Figure 3 a significant impact on the amount of cash flow when recognizing this investment as profitable, is the number of users of this heat recovery system. In a situation where the percentage of accommodation used is $75 \%$ and $100 \%$, it turns out that the project can be considered beneficial to the investor, regardless of the adopted source of heat. The installation of a DWHR system in a configuration with an electric heater seems to be the most cost-effective, as it generates the highest profits in each of the cases analyzed, regardless of the occupancy rate of the hotel. This may be due to the fact that the price of electricity as a heat carrier is relatively high compared to the purchase price of natural gas or biomass in the form of wood pellets. The smallest cash flows are observed in the case of variant B, hence the lowest values of $\Sigma$ PV-NCF were obtained in the end, and this variant is the least favorable for the investor.

The exact value of the NPV indicator, as well as the results of the calculation of the other criteria taken into account in assessing the financial effectiveness of investments such as: Internal Rate of Return IRR, Profitability Index PI, Simple Pay Back Period SPBP and Discounted Pay Back Period DPBP are summarized in Table 6.

Table 6. The results of calculations of investment financial performance indicators.

\begin{tabular}{|c|c|c|c|c|c|c|}
\hline Variant & Option & NPV [€] & IRR [\%] & PI [-] & SPBP [yrs] & DPBP [yrs] \\
\hline \multirow{4}{*}{$\mathbf{A}$} & $25 \%$ & $-7046,42$ & $0,17 \%$ & 0,49 & 29,34 & - \\
\cline { 2 - 7 } & $50 \%$ & $-242,94$ & $4,86 \%$ & 0,98 & 16,78 & 37,43 \\
\cline { 2 - 7 } & $75 \%$ & 6565,69 & $8,38 \%$ & 1,47 & 11,78 & 18,23 \\
\cline { 2 - 7 } & $100 \%$ & 13374,22 & $11,43 \%$ & 1,96 & 9,08 & 12,41 \\
\hline \multirow{4}{*}{ B } & $25 \%$ & $-8977,59$ & $-1,58 \%$ & 0,35 & 36,47 & - \\
\cline { 2 - 7 } & $50 \%$ & $-4095,23$ & $2,51 \%$ & 0,70 & 22,21 & - \\
\cline { 2 - 7 } & $75 \%$ & 787,19 & $5,43 \%$ & 1,06 & 16,07 & 33,34 \\
\cline { 2 - 7 } & $100 \%$ & 5669,56 & $7,86 \%$ & 1,41 & 12,61 & 20,39 \\
\hline \multirow{4}{*}{$\mathbf{C}$} & $25 \%$ & 646,39 & $5,37 \%$ & 1,05 & 15,59 & 31,01 \\
\cline { 2 - 7 } & $50 \%$ & 15152,79 & $12,45 \%$ & 2,09 & 8,25 & 10,90 \\
\cline { 2 - 7 } & $75 \%$ & 29659,18 & $18,55 \%$ & 3,14 & 5,61 & 6,75 \\
\cline { 2 - 7 } & $100 \%$ & 44165,58 & $24,40 \%$ & 4,19 & 4,25 & 4,90 \\
\hline
\end{tabular}

The value of the Net Present Value parameter results directly from the graphs shown in Figure 1, Figure 2 and Figure 3, so the conclusions are analogous.

In analyzing the IRR indicator, the investment is profitable for variants A and B with options from $75 \%$ of the use of beds, and for option $\mathrm{C}$ for all options analyzed. When the hotel is fully occupied, the IRR value is $24,4 \%$, almost five times the assumed discount rate. The same conclusions come to mind when analyzing the PI index values. The $\mathrm{C}$ option is definitely the most advantageous, and for the remaining heat sources and only with the $75 \%$ and $100 \%$ occupancy, with a view to higher profits in option A than B.

The SPBP parameter was also estimated, i.e. the payback period of the investment funds involved, which for the analyzed cases ranged from 4,25 for the most profitable venture: option C, option $100 \%$ to 36,47 years for the least profitable undertaking: option B, option $25 \%$. Apart from the least favorable case, for all others the time needed to recover expenditure is acceptable and does not exceed the 30 -year period taken for this analysis. A more accurate indicator is DPBP, which is the payback period taking into account the discount account, but after implementation in the calculation of the change in the time value of money, the number of years needed to recover the expenditure spent on the investment has been significantly extended, and in some cases was so large that the estimation values have become impossible. 
Taking into account the DPBP parameter, the profitability of the project after the option C seems to be small.

\section{Summary}

The conducted research has shown that the cost-effectiveness of the DWHR system in a hotel is unambiguous when the heat carrier for the hot water supply system is electric energy and brings considerable financial benefits to the investor. In other cases, the profitability of the project depends on the occupancy rate of the hotel. If a large number of guests use the accommodation, the investment is always profitable, regardless of the heat source.

The installation of a heat recovery system from graywater does not require significant investment means compared to other installations in a hotel facility, and it has many advantages, such as no need to operate or provide electricity (the installation works always and automatically), yet the biggest advantage is the positive effect on the external environment, because every kilowatt-hour of saved energy translates into a lower emission of pollutants into the atmosphere, therefore equiping every hotel with such a system should be considered to, especially in larger facilities where both water consumption and the amount of energy recovered are high.

\section{References}

1. Directive 2002/91/EC of the European Parliament and of the Council of 16 December 2002 on the energy performance of buildings

2. $\operatorname{COM(2015)~} 80$ final communication on A Framework Strategy for a Resilient Energy Union with a Forward-Looking Climate Change Policy (European Commission, Brussels, 2015)

3. SWD(2016) 24 final communication on EU Strategy for Heating and Cooling (European Commission, Brussels, 2016)

4. K. Pochwat, E3S Web Conf. 17, 00075 (2017)

5. M. Starzec, J. Dziopak, Underground Infrastructure of Urban Areas 4, 181-191 (2018)

6. A. Stec, A.Mazur, D. Słyś, E3S Web Conf. 22, 00168 (2017)

7. Q. Zhang, Z. Yang, N. Li, R. Feng, YD. Gao, Energ. Buildings 167, 136-151 (2018)

8. S. Kordana, D. Słyś, J. Dziopak, J. Clean. Prod. 82, 58-69 (2014)

9. A. Stec, S. Kordana, D. Słyś, J. Clean. Prod. 151, 193-205 (2017)

10. R. Manouchehri, M.R. Collins, Energ. Buildings 130, 1-7 (2016)

11. D. Słyś, S. Kordana, Energ. Buildings 71, 1-11 (2014)

12. Ecodrain Brochures, https://ecodrain.com/en/ (accessed February 2018)

13. W. Rogowski, Rachunek efektywności inwestycji, (Wolters Kluwer Poland, Warsaw, 2013)

14. M. Sierpińska, T. Jachna, Ocena przedsiębiorstwa wedtug standardów światowych, (Polish Scientific Publishers PWN, Warsaw, 2004)

15. Journal of Laws of 2015, item 376, Regulation of the Minister of Infrastructure and Development of 18 February 2015 on the methodology for determining the energy performance of a building or part of a building and energy performance certificates

16. S. Fidewicz, Biblioteka Źródłowa Energetyki Prosumenckiej, Available: http://ilabepro.polsl.pl/spep/raporty/energetyka-odpadowa/Fidewicz\%20Sz. \%20Ciep\%C5\%82o\%20odpadowe\%20w\%20domu..pdf (accessed February 2018) 